\title{
Numerical investigation of advanced gas turbine combined cycle coupled with high-temperature nuclear reactor and cogeneration unit
}

\author{
Marek Jaszczur*, Michat Dudek, Zygmunt Kolenda \\ AGH University of Science and Technology, Faculty of Energy and Fuels, Department of Fundamental Research in Energy \\ Engineering, Mickiewicza 30, 30-059 Kraków, Poland
}

\begin{abstract}
In the European Union by 2050 , more than $80 \%$ of electricity should be generated using nongreenhouse gases energy technology. Nuclear power systems share at present about $15 \%$ of the power market and this technology can be the backbone of a carbon-free European power system. Energy market transitions are similar to global pathways were analysed in the Intergovernmental Panel on Climate Change report. From a practical point of view currently, the most advanced and most effective technology for electricity generation is based on a gas turbine combined cycle. This technology in a normal way uses natural gas, synthesis gas from the coal gasification or crude oil processing products as the energy carriers but at the same time, such system emits sulphur oxides, nitrogen oxides, and $\mathrm{CO}_{2}$ to the environment. In the present paper, a thermodynamic analysis of environmentally friendly power plant with a high-temperature gas nuclear reactor and advanced configuration of gas turbine combined cycle technology is investigated. The presented analysis shows that it is possible to obtain for proposed thermal cycles an efficiency higher than $50 \%$ which is not only more than could be offered by traditional coal power plant but much more than can be proposed by any other nuclear technology.
\end{abstract}

\section{Introduction}

The present European Union decarbonisation strategy consider nuclear energy as a very promised carbon-free solution of combined heat and power generation [1]. Cogeneration always contributes to the reduction of primary energy consumption and gain plant efficiency. At present most of nuclear power plant work with the thermal efficiency around 33\% [2-4]. In a nuclear power plant system by turbine cycle system modification, it is possible to excess heat for district heating. This concept was investigated for the first time in the 1970s and continue up to the earliest 1980s. Several studies were done using Russian Water-Water Energetic Reactors or Light Water-Cooled Graphite moderated Reactor [5]. Another example is the Canadian CANDU reactor, generated district heat and electricity or Pressurized Water Reactor which produce heat and power in Beznau, Switzerland. However, due to a large number of safety problems, this solution never become popular.

Recently this option again has been taken into account which was expressed by Nuclear Energy Agency [6]. This Agency launched a project to assess the role and economics of nuclear cogeneration for a future environmental friendly low-carbon power plant [7]. Following the construction of the first nuclear plants in the 1950s and 1960s, this technology obtains rapid growth from the 1970s. The possible low cost of energy from a nuclear power plant was bolstered by the oil crisis of the 1970s. This situation led to concerns about energy safety. Later development in the 1990s was caused by the accidents at Three Mile Island and Chernobyl, as well as by lower than predicted energy consumption growth.

At present, there is a limited number of promising nuclear technologies which are in different stages. Research studies on nuclear cogeneration have been performed by Hanuszkiewicz-Drapala and Jedrzejewski [8]. Two of the interesting solutions are SMR small modular reactors, which guarantee a realistic improvement in reactor flexibility and efficiency and High-Temperature gas Reactor (HTR).

High-Temperature Nuclear Reactor is an ideal solution for energy, district heating as well as for hightemperature process heat applications. The outlet temperature of primary gas helium coolant is around $750^{\circ} \mathrm{C}$ in the case on HTR and up to $1000^{\circ} \mathrm{C}$ for VHTR configuration. Most of the studies conducted on the implementation of HTR were done in the United States, France, Japan and Russia. At present, HTR development programs are in progress in many countries $[9,10]$. Due to HTR features this technology provides unique and unobtainable the energy conversion safety with thermal efficiency higher than offered by any other nuclear technology at present $[11,12]$. In experts opinion, this

\footnotetext{
* Corresponding author: jaszczur@agh.edu.pl
} 
technology seems to be an excellent solution $[13,14]$ and could be implemented in the industry sector, power generation sector and for district heating in the near future [15].

In this research studies, the authors developed a new combined power cycle for the gas turbine and steam turbine coupled with a high-temperature nuclear reactor. The objective is to find the optimal configuration for the power cycle with cogeneration and a different number of pressure Heat Recovery Steam Generator units.

\section{Mathematical model}

The computational model for the system analysis consists of the thermodynamic equations for HTR coupled with a gas turbine (GT), steam turbine (ST) with steam regeneration and heat recovery steam generation (HRSG). In Figure 1 the analysed cycle has been presented in detail.

In the present study, the following equations were used: Thermal nuclear reactor power was calculated from:

$$
\dot{Q}_{r}=\dot{m}_{H e} c_{p H e}\left(T_{o u t}-T_{\text {in }}\right)
$$

where: $m_{1 H e}, c_{p H e}$ - helium mass flowrate and specific heat, $T_{\text {out }}, T_{\text {in }}$ - reactor outlet and inlet temperature. The heat flux in the primary loop can be calculated as:

$$
\dot{Q}_{r}=\dot{m}_{H e}\left(h_{1}-h_{2}\right)
$$

where: $h_{1}, h_{2}$ - helium specific enthalpy at the inlet to and outlet from the heat exchanger hot side. The heat flux in the secondary loop is equal to:

$$
\dot{Q}_{R}=\dot{m}_{2 H e}\left(h_{4}-h_{3}\right)
$$

where: $m_{2 \mathrm{He}}$ - helium mass flowrate, $h_{3}, h_{4}$ - enthalpy at the inlet to and outlet from the heat exchanger cold side. High-temperature heat exchanger (HE) enthalpy balance is as follows:

$$
\begin{aligned}
& \dot{m}_{1 \mathrm{He}} c_{p \mathrm{He}}\left[T_{1}-T_{0}\right]+\dot{m}_{2 \mathrm{He}} c_{p H e}\left(T_{3}-T_{0}\right)=\mathrm{He}_{(4)^{\mathrm{He}}} \\
& =\dot{m}_{1 \mathrm{He}} c_{p \mathrm{He}}\left(T_{2}-T_{0}\right)+\dot{m}_{2 \mathrm{He}} c_{p H e}\left(T_{4}-T_{0}\right)
\end{aligned}
$$

where: $m_{1 H e} / m_{2 H e}$ - helium mass flow at the hot and cold side, $T_{0}$-reference temperature, $T_{1} / T_{2}$-inlet to or outlet from temperature to/from heat exchanger hot side, $T_{3} / T_{4}$ - inlet to or outlet from temperature to/from heat exchanger cold side. Steam turbine electrical power was calculated as follows:

$$
\begin{gathered}
N_{S T}=\eta_{g e n} \eta_{m e c h}\left(\sum_{i=1}^{2} \eta_{i} \eta_{m e c h} \dot{m}_{p i} w_{i}\right)- \\
-\sum_{i=1}^{2}\left[\left(\dot{m}_{w i} w_{p i}\right) /\left(\eta_{i p} \eta_{m e c h}\right)\right]
\end{gathered}
$$

$\left[\left(m_{w i} w_{p i}\right)\right.$ wh(eme: $\left.\eta_{m G T_{h}}\right)$ gas turbine electrical power, $N_{S T}$ - steam

$$
\text { p tum }
$$
turbine first/second/third step electrical power, $N_{p i}$ pumps energy demand, $N_{b}$ - fan energy demand.

The model assumptions for numerical analysis and model constants for selected components of the power loop from Figure 1 are presented in Table 1. The

where: $\eta_{\text {mech }}, \eta_{\text {gen }}$-generator mechanical and electrical efficiency, $\eta_{i}, \eta_{i p}$ - isentropic efficiency for steam turbine and pump, $\dot{m}_{p i}{ }^{-}$steam mass flowrate, $w_{p i}$ - water pumps work, $\dot{m}_{w i}{ }^{-}$water mass flow, $w_{i}-$ high/middle/low-pressure steam turbine work. Gas turbine (GT) electrical power was calculated from the following equation:

$$
N_{G T 1}=\eta_{g e n} \dot{m}_{2 H e}\left(\eta_{\mathrm{i} G T} \eta_{m e c h} w_{G T}-w_{C} /\left[\eta_{i C} \eta_{m e c h}\right]\right)
$$

where: $\eta_{g e n}, \eta_{\mathrm{i} G T}, \eta_{\text {mech }}$ - gas turbine electrical, isentropic and mechanical efficiency, $w_{G T}$ - gas turbine work, $\eta_{i C}$ compressor isentropic efficiency, $w_{C}$ - compressor work.

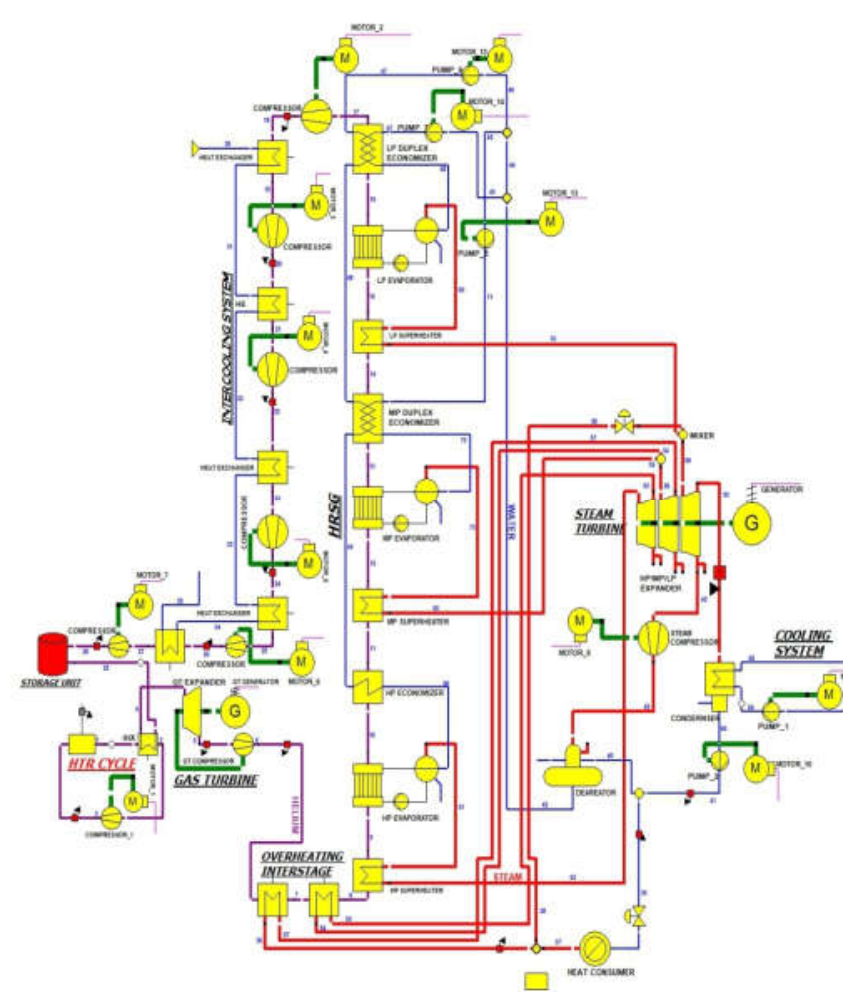

Fig. 1. High-temperature reactor coupled with a gas turbine combined cycle and with triple pressure level HRSG unit.

The presented in Figure 1 cycle thermal efficiency was calculated as follows:

$$
\eta_{c}=\frac{N_{G T}+N_{S T}+\eta \dot{Q}_{C O G}-\sum_{i / 1}^{n} N_{p i}-N_{b}}{Q_{R}}
$$


numerical simulations were done using Ebsilon Pro software. The detailed model and calculation procedure as well as all essential system components description with governing equations can be found in other authors work [16-19].

In the presented system, the Heat Recovery Steam Generator HRSG is an essential system component and its modification or different implementation significant affect the performance of the steam turbine circuit as well as the efficiency of the cycle. The largest heat exchange takes place in the economiser part for the low-pressure level and in the evaporator part for the high-pressure level. The remaining heat from the gas turbine exhaust gases can be used in a heat recovery steam generator unit to produce high-quality steam This steam can be used in industrial processes or for electricity generation using the steam turbine. In the present system, three different configurations were analysed: single, dual and triple pressure heat recovery steam generator units are used without and with interstage steam overheating units to show its impact on the final results. A detailed computational model for the HRSG unit with heat transfer equations is presented in $[16,17,20]$.

Table 1. Assumptions for thermodynamic calculations.

\begin{tabular}{|c|c|c|}
\hline Thermal Power of HTR & 300 & $\mathrm{MW}_{\text {th }}$ \\
\hline Coolant in the main primary loop & $\mathrm{He}$ & - \\
\hline Working fluid in the secondary loop & $\mathrm{He}$ & - \\
\hline Reactor outlet temperature & 850 & ${ }^{\circ} \mathrm{C}$ \\
\hline Reactor coolant pressure & 7 & $\mathrm{MPa}$ \\
\hline $\begin{array}{l}\text { The mass flow rate of helium in the } \\
\text { primary loop }\end{array}$ & 128 & $\mathrm{~kg} / \mathrm{s}$ \\
\hline Inlet pressure before Gas Turbine & 6.95 & $\mathrm{MPa}$ \\
\hline Outlet pressure after Gas Turbine & 2 & $\mathrm{MPa}$ \\
\hline $\begin{array}{l}\text { The mass flow rate of helium in the } \\
\text { secondary loop }\end{array}$ & 104.5 & $\mathrm{~kg} / \mathrm{s}$ \\
\hline Gas Turbine mechanical efficiency & 0.99 & - \\
\hline Gas Turbine isentropic efficiency & 0.9 & - \\
\hline The steam Turbine inlet temperature & 385 & - \\
\hline Steam Turbine inlet pressure & 20.5 & $\mathrm{MPa}$ \\
\hline The mass flow rate of steam & 35.80 & $\mathrm{~kg} / \mathrm{s}$ \\
\hline Steam turbine mechanical efficiency & 0.998 & - \\
\hline Steam turbine isentropic efficiency & 0.88 & \\
\hline Generator electric efficiency & 0.9856 & - \\
\hline $\begin{array}{l}\text { The outlet temperature of water from } \\
\text { the condenser }\end{array}$ & 23.96 & ${ }^{\circ} \mathrm{C}$ \\
\hline Pressure inlet at feedwater preheater & $0.5 / 0.9$ & bar \\
\hline
\end{tabular}

\section{Results and discussion}

The results presented in Figures 2-3 are based on the layout of GTCC (see Figure 1) with single, dual, triple pressure heat recovery steam generation system with cogeneration coupled with HTR and with various subconfigurations (with and without interstage steam overheating).

One can infer from Figure 2(a) that system without interstage steam overheating is able to generate more than $211.51 \mathrm{MW}_{\mathrm{e}}$ of electrical power. However, when the system is equipped with single or dual HRSG unit electrical energy production obtained from numerical calculations equals to $194.25 \mathrm{MW}_{\mathrm{e}}$ and $204.55 \mathrm{MW}_{\mathrm{e}}$ respectively what is shown in Figure 2(a). It can be seen a decrease in the electrical power when single or dual pressure heat recovery steam generation unit is used.
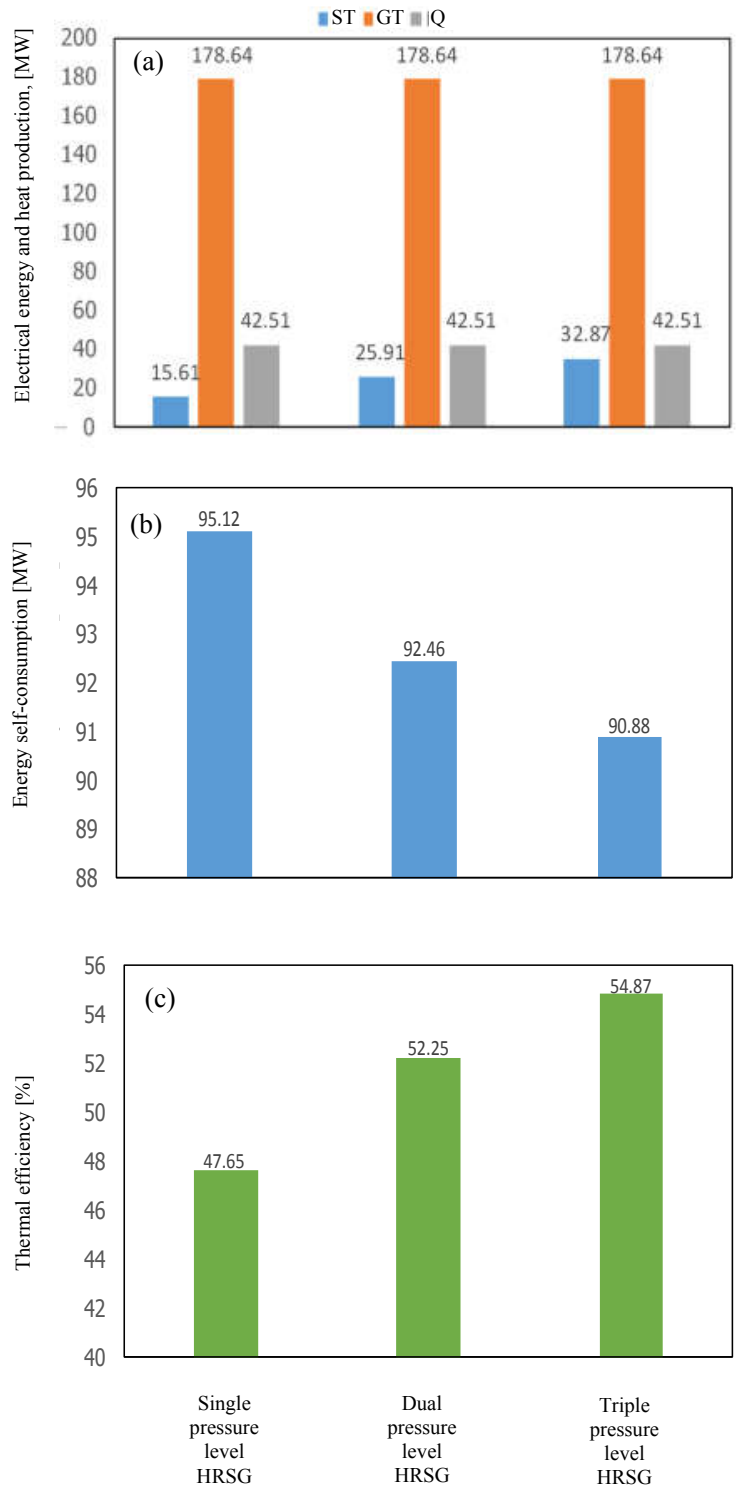

Fig. 2. Electrical energy from GT, ST and heat production Q (a), energy self-consumption (b) and overall system thermal efficiency (c) for the system with 1P, 2P, 3P pressure level HRSG and without interstage steam overheating. 
The analysed power cycle with cogeneration is able to generate power with thermal efficiency in the range from $47.65 \%, 52.25 \%$ up to $54.87 \%$ depends on the configuration i.e. (single-1P, dual-2P, triple-3P) pressure level Heat Recovery Steam Generator respectively what can be seen in Figure 2(c). For the systems with interstage steam overheating and with cogeneration, gas turbine, electrical power generation is similar while power generation by the steam turbine differs. The system with cogeneration and with interstage steam overheating (see Figure 3) is able to generate about 195.92, 206.67 and $212.96 \mathrm{MW}_{\mathrm{e}}$ of electrical power for 1P, 2P and 3P HRSG respectively what is shown in Fig. 3(a). The system thermal efficiency with cogeneration and for sub-configuration with single, dual or triple HRSG unit obtain thermal efficiency equal to $43.8 \%$, $50.29 \%$ and $55.73 \%$ respectively.
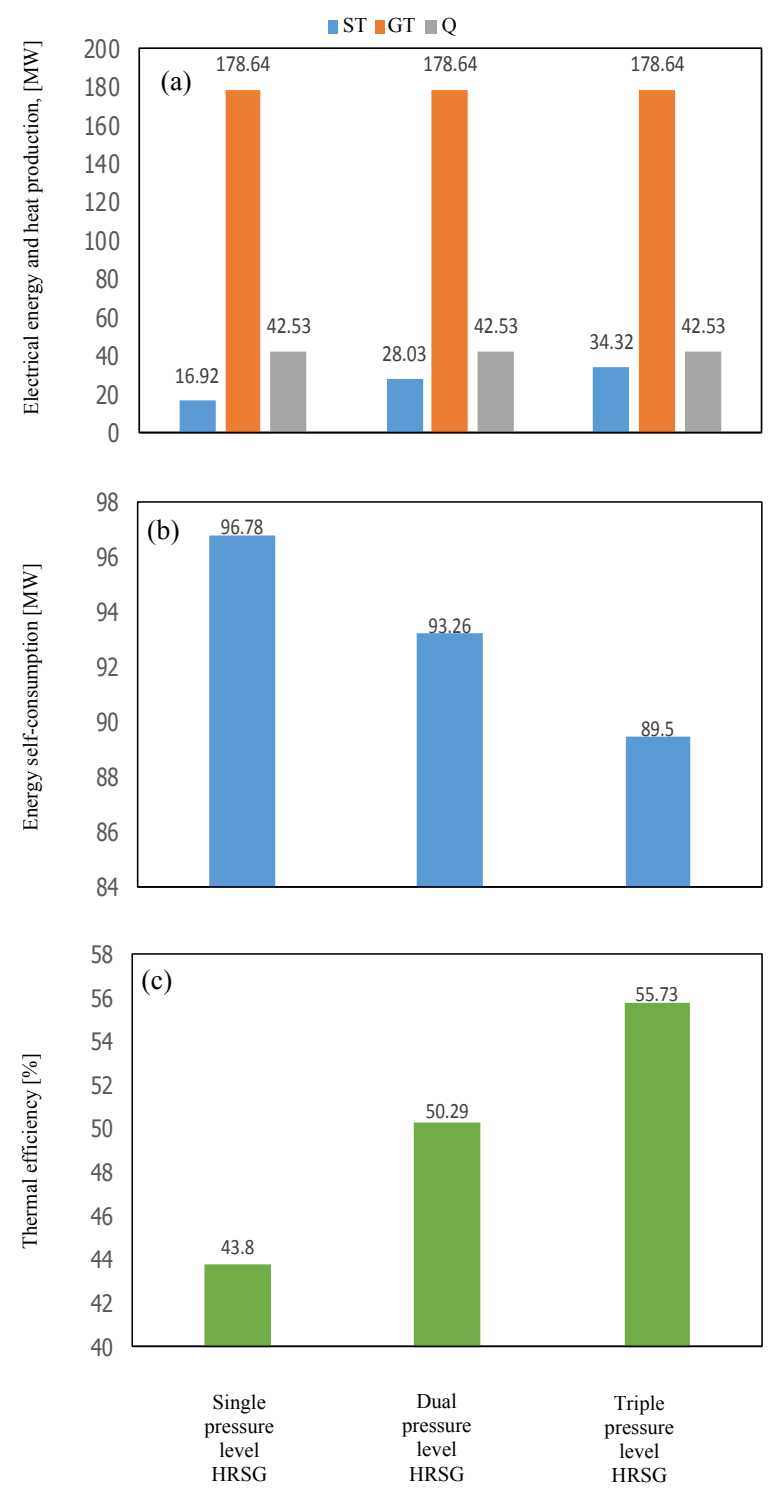

Fig. 3. Electrical energy from GT, ST and heat production Q (a), energy self-consumption (b) and overall system thermal efficiency (c) for the system with 1P, 2P, 3P pressure level HRSG and with interstage steam overheating

\section{Conclusions}

The gas turbine combined cycle coupled with HTR is a promising solution in the field of emission-free electrical energy production and high-performance power plant. The industrial application of such systems can produce electricity with high thermal efficiency depends on the exact sub-solution including interstage steam overheating, cogeneration, single, dual and triple pressure-level HRSG unit. The proposed solution is based on one of the most advanced technologies which give the possibility to generate electrical power and hightemperature technological heat as well as heat for district heating without pollutant generation and with efficiency higher than could be offered by a classical coal or lignite based power plant or any other nuclear power plant technology (for example PWR, BWR).

Thermodynamic cycle for presented system shows that it is possible to obtain for the case with cogeneration and with dual pressure-level HRSG which is the best solution from an economic point of view the thermal efficiency equal to $52.25 \%$. The system with triple pressure-level HRSG unit offers efficiency 2.6 p.p. higher however additional cost it is not always economically justified. On the other hand, 3P HRSG system with cogeneration and with interstage steam overheating can obtain efficiency as high as $55.73 \%$.

ACKNOWLEDGMENTS. The present work was partially supported by the Polish Ministry of Science (Grant AGH No. 16.16.210.476).

\section{References}

1. World Energy Council, World Energy Resources (2016)

2. Energy, N, Technology Roadmap, Springer Reference (2015)

3. International Energy Agency, Energy Technology Perspectives, Int. Energy Agency (2015)

4. M. Jaskólski, A. Reński, T. Minkiewicz, Thermodynamic and economic analysis of nuclear power unit operating in partial cogeneration mode to produce electricity and district heat. Energy, 141 (2017)

5. F. M. Mitenkov, E. V. Kusmartsev, Nuclear Heat Applications in Russia: experience, status and prospects No. IAEA-TECDOC_-1056 (1998)

6. Nuclear Energy Agency, On the role and economics of nuclear cogeneration in a low carbon energy future NEA/NDC, 22, 4.52 (2012)

7. J. M. Noh, H. Paillere, V. Sozoniuk, On the role and economics of nuclear cogeneration in a low carbon energy future. In: IAEA tech. Meet. Econ. Anal. High temp. Gas cool. React. Small medium Sized reactor, Vienna (2015)

8. M. Hanuszkiewicz-Drapała, J. Jędrzejewski, Thermodynamic analysis of a co-generation system 
with a high-temperature gas cooled nuclear reactor, Journal of Power Technologies, 95 (2015)

9. Next Generation Nuclear Plant Research and Development Program Plan, Idaho National Laboratory (2015)

10. International Prismatic Block HTGR Commercial Deployment Meeting Summary in Washington DC, March 8-10, (2016)

11. C. F. McDonald, Power conversion system considerations for a high efficiency small modular nuclear gas turbine combined cycle power plant concept (NGTCC), Applied Thermal Engineering, 73 (2014)

12. Z. Zuoyi, et al., The Shandong Shidao Bay $200 \mathrm{MWe}$ high-temperature gas-cooled reactor pebble-bed module (HTR-PM) demonstration power plant: an engineering and technological innovation, Engineering, 2 (2016)

13. V . Zare, et al., Energy and exergy analysis of a closed Brayton cycle-based combined cycle for solar power tower plants, Energy Conversion and Management, 128 (2016)

14. C. Luo,, et al., A novel nuclear combined power and cooling system integrating high temperature gascooled reactor with ammonia-water cycle, Energy Conversion and Management, 87 (2014)

15. G. Locatelli, et al., Generation IV nuclear reactors: Current status and future prospects, Energy Policy, 61 (2013)

16. M. Dudek, Z. Kolenda, M. Jaszczur, W. Stanek, Thermodynamic Analysis of Power Generation Cycles With High-Temperature Gas-Cooled Nuclear Reactor and Additional Coolant Heating Up to $1600^{\circ} \mathrm{C}$, Journal of Energy Resources Technology, 140 (2018)

17. M. Jaszczur, M. A. Rosenb, T. Śliwa, M. Dudek, L. Pieńkowski, Hydrogen production using high temperature nuclear reactors: Efficiency analysis of a combined cycle, International Journal of Hydrogen Energy, 41 (2016)

18. M. Dudek, M. Jaszczur, An analysis of the thermodynamic cycles with high-temperature nuclear reactor for power generation and hydrogen coproduction, E3S Web of Conferences, 14 (2017)

19. Jaszczur, M. et al., 2018, An analysis of hightemperature nuclear reactor coupled with gas turbine combined cycle, MATEC Web of Conferences, 240, pp. 05010.

20. M. Jaszczur, M. Dudek, Z. Kolenda, Thermodynamic analysis of high temperature nuclear reactor coupled with advanced gas turbine combined cycle, Thermal Science, 23 (2019) 